\title{
DOUBLE-BLIND EVALUATION OF BUPRENORPHINE HYDROCHLORIDE FOR POST-OPERATIVE PAIN
}

\author{
Allen B. Dobkin, Barbara Esposito, and Carole Philbin
}

IN A PREVIOUS STUDY it was found that buprenorphine hydrochloride is a potent analgesic and that severe post-operative pain is relieved appreciably for at least six hours by $0.4 \mathrm{mg}$ or less. ${ }^{1}$ This confirmed impressions gained from studies on animals and man currently in progress abroad. ${ }^{2,3}$

The purpose of this study was to compare the analgesic activity of buprenorphine hydrochloride $0.2 \mathrm{mg}$ and $0.4 \mathrm{mg}$ against each other and also against the usual standard, morphine sulphate $5 \mathrm{mg}$ and $10 \mathrm{mg}$, each of which was given as a single intramuscular injection following selected major surgical procedures associated with severe post-operative pain.

\section{METHOD}

A double-blind randomly assigned comparison was done of four groups of 40 patients, each of whom gave written informed consent agreeing to participate in the evaluation by accepting one intramuscular dose of either buprenorphine $(0.2$ or $0.4 \mathrm{mg}$ ) or morphine ( 5 or $10 \mathrm{mg}$ ) from identical serially numbered vials, if moderate to severe pain occurred in the recovery room after awakening from anaesthesia following abdominal surgery. A patient was admitted to this comparative study provided pre-operative laboratory studies were within normal limits, the investigator agreed that the patient was having severe pain post-operatively and the patient requested medication for the pain. Exclusions were specified to eliminate women of childbearing age, patients undergoing narcotic maintenance treatment or who had a history of tolerance or addiction to analgesic drugs, neurosurgery, cardiac surgery and any patient who had severe disease of vital organs, endocrine disease or haematologic disease. Those who had limited mental competence or difficulty in answering questions at the initial interview were also excluded. Patients excluded from the study received medication for pain according to standard procedures in the recovery room.

No other analgesic medication was given to a patient once medicated in the test, unless severe pain was not relieved or unless severe pain recurred within two hours.

Pain intensity was scored as $0=$ none; $1=$ mild; $2=$ moderate; $3=$ severe; and $4=$ very severe. Pain relief was scored as $0=$ no relief; $1=$ slight relief; $2=$ moderate relief; $3=$ good relief; and $4=$ complete relief. ${ }^{4-7}$ Scoring was done routinely at 30 minutes and then hourly for six hours. If no additional medication was required, the patient was kept under direct surveillance for 12 hours. Patients

From: Department of Anesthesiology, State University of New York, Upstate Medical Center, State University Hospital, Syracuse, New York, 13210, U.S.A. 
TABLE I

VITAL DATA FROM FOUR GROUPS OF PATIENTS WHO RECEIVED BUPRENORPHINE HYDROCHLOKIDE $(0.2$ OR $0.4 \mathrm{mg}$ ) OR MORPHINE ( 5 OR $10 \mathrm{mg}$ )

\begin{tabular}{|c|c|c|c|c|c|c|c|}
\hline & \multicolumn{2}{|c|}{ Age } & \multirow{2}{*}{$\begin{array}{c}\begin{array}{c}\text { Weight } \\
\text { (kg) }\end{array} \\
42 \\
110 \\
70\end{array}$} & \multirow{2}{*}{$\begin{array}{c}\text { Sex } \\
M: 10 \\
F: 29^{*} \\
N=39\end{array}$} & \multirow{2}{*}{$\begin{array}{l}\text { Race } \\
\text { W: } 33 \\
\text { N: } \quad 6\end{array}$} & $\begin{array}{l}\text { Initial } \\
\text { pain } \\
\text { intensity }\end{array}$ & Remedication \\
\hline $\begin{array}{l}\text { Buprenorphine } \\
0.2 \mathrm{mg}\end{array}$ & $\begin{array}{l}\text { Low: } \\
\text { High: } \\
\text { Mean: }\end{array}$ & $\begin{array}{l}22 \\
85 \\
47\end{array}$ & & & & $\begin{array}{r}\text { M-S: } \quad 2 \\
\text { S: } 37\end{array}$ & $\begin{array}{rr}<2 \mathrm{hr}: \quad 4 \\
2-5: \quad 15 \\
>5 \mathrm{hr}: 16 \\
>12 \mathrm{hr}:\end{array}$ \\
\hline $\begin{array}{l}\text { Buprenorphine } \\
0.4 \mathrm{mg}\end{array}$ & $\begin{array}{l}\text { Low: } \\
\text { High: } \\
\text { Mean: }\end{array}$ & $\begin{array}{l}18 \\
80 \\
45\end{array}$ & $\begin{array}{l}40 \\
98 \\
67\end{array}$ & $\begin{array}{l}\mathrm{M}: 11 \\
\mathrm{~F}: 29 \\
\mathrm{~N}=40\end{array}$ & $\begin{array}{lr}W: & 39 \\
N: & 1\end{array}$ & $\begin{array}{r}\text { M-S: } \quad 0 \\
\text { S: } 40\end{array}$ & $\begin{array}{rr}<2 \mathrm{hr}: & 6 \\
2-5: & 19 \\
>5 \mathrm{hr}: & 7 \\
212 \mathrm{hr} & 8\end{array}$ \\
\hline $\begin{array}{l}\text { Morphine } \\
5 \mathrm{mg}\end{array}$ & $\begin{array}{l}\text { Low: } \\
\text { High: } \\
\text { Mean: }\end{array}$ & $\begin{array}{l}21 \\
74 \\
44\end{array}$ & $\begin{array}{r}39 \\
117 \\
73\end{array}$ & $\begin{array}{l}\mathrm{M}: \quad 9 \\
\mathrm{~F}: \quad 31 \\
\mathrm{~N}=40\end{array}$ & $\begin{array}{l}\text { W: } 38 \\
\text { N: } \quad 2\end{array}$ & $\begin{array}{r}\text { M-S: } \quad 1 \\
\text { S: } 39\end{array}$ & $\begin{array}{cr}<2 \mathrm{hr}: & 17 \\
2-5: & 15 \\
>5 \mathrm{hr}: & 7 \\
>12 \mathrm{hr} & \end{array}$ \\
\hline $\begin{array}{l}\text { Morphine } \\
10 \mathrm{mg}\end{array}$ & $\begin{array}{l}\text { Low: } \\
\text { High: } \\
\text { Mean: }\end{array}$ & $\begin{array}{l}18 \\
76 \\
45\end{array}$ & $\begin{array}{r}40 \\
118 \\
72\end{array}$ & $\begin{array}{l}\mathrm{M}: \quad 11 \\
\mathrm{~F}: \quad 29 \\
\mathrm{~N}=40\end{array}$ & $\begin{array}{lr}\text { W: } & 37 \\
\mathrm{~N}: & 3\end{array}$ & $\begin{array}{r}\text { M-S: } \quad 3 \\
\text { S: } 37\end{array}$ & $\begin{array}{rr}<2 \mathrm{hr}: & 5 \\
2-5: & 23 \\
>5 \mathrm{hr}: & 7 \\
>12 \mathrm{hr}: \quad 4\end{array}$ \\
\hline
\end{tabular}

* 1 patient was not medicated after the ampoule was opened because, on reconsideration, the amount of pain was overestimated.

who appeared to be asleep during the study period were aroused for each interview. ${ }^{5}$

Other observations recorded included auscultatory blood pressure, pulse rate, respiratory rate, degree of sedation $(1=$ alert; $2=$ mildly drowsy; $3=$ moderately drowsy; and $4=$ asleep) and side effects ("is anything bothering you?") including objective signs such as miosis, retching, vomiting, and sweating.

All data derived from interviews were recorded along with notes of other observations and subsequently analyzed statistically. ${ }^{8,9}$

The large majority of the patients in this study were premedicated with diazepam and atropine, received enflurane-nitrous oxide anaesthesia following induction with thiopentone and pancuronium and had mechanically controlled pulmonary ventilation. At the end of the operation, residual effect of the muscle relaxant was reversed with atropine and neostigmine $(1: 2)$ prior to extubation.

\section{Results}

Using analyses of variance or chi-square tests, the four treatment groups were found to be comparable with respect to the demographic variables - age, sex, weight, height, and race. Over-all, for the 159 patients who received the drug in the test, 118 were female and 147 were caucasian. The average height and weight was $165 \mathrm{cms}$ and $70 \mathrm{kgs}$, respectively. The average age was 45 years with a range of 18 to 85 ( see Table I).

To determine comparability of treatment groups at baseline, an analysis of variance was performed on the pre-drug pain intensity scores. Pain was severe in 96 per cent of all patients and in at least 92 per cent of each group, indicating that the groups were comparable. 


\section{BUPRENORPHINE DOUBLE BLIND STUDY}

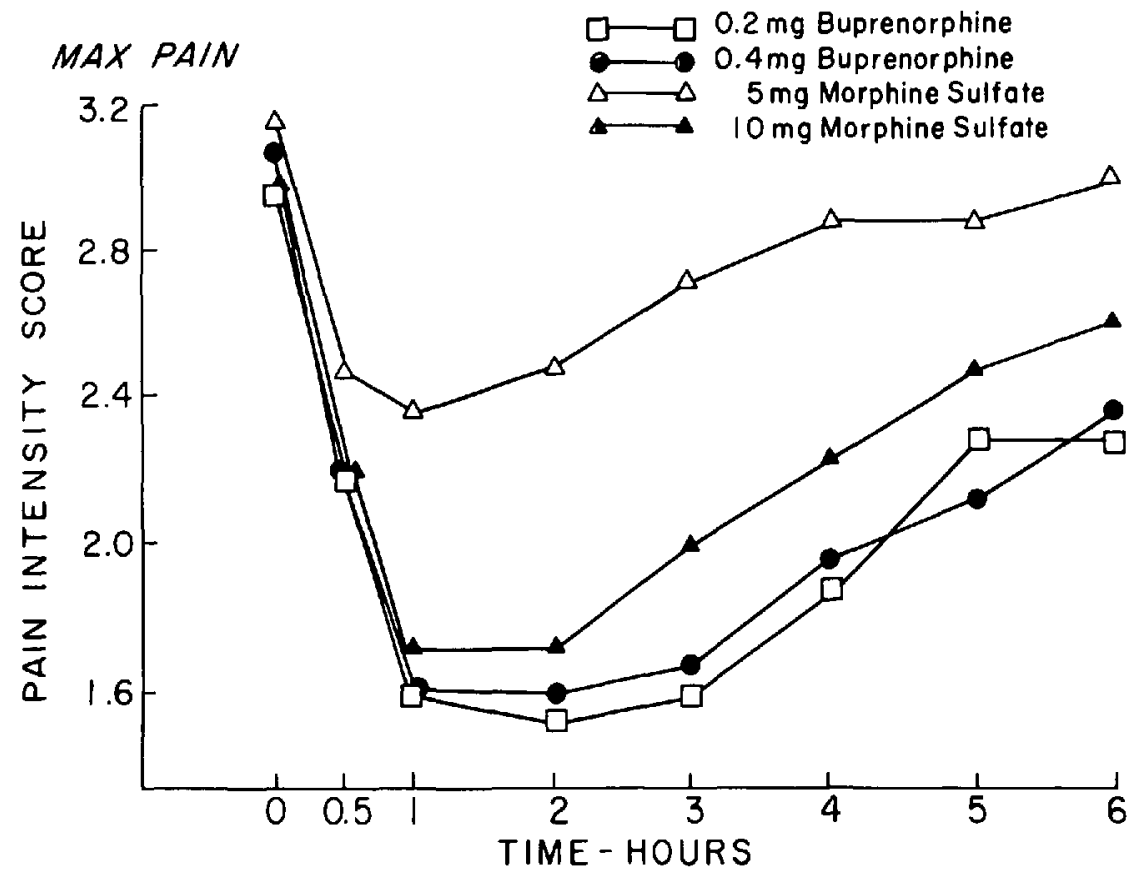

Figure 1. Mean pain intensity scores with buprenorphine and morphine during first six hours after intramuscular medication: $0=$ none; $1=$ mild; $2=$ moderate; $3=$ severe; $4=$ very severe.

The average pain reduction over three and six hours (AVPRED 3, AVPRED 6, AVPREL 3, AVPREL 6) were analyzed as they were in the report of the open study. ${ }^{1}$ An additional parameter, R-Time, was also analyzed. R-Time is the duration of relief as measured by the time interval between administration of test drug and the administration of the next analgesic. If no analgesic was given within 12 hours, a value of 13 was assigned for purposes of analysis. To compare the four treatment groups, each of these five parameters were analyzed by an analysis of variance with blocking on the pre-drug pain severity. The mean response for each treatment group was adjusted for differences in the pre-drug pain intensity. Paired comparisons of the four treatment groups were performed on the adjusted means, using two-sided t-tests.

The comparisons show that there were significant differences among the four treatment groups for all five parameters. The pair comparisons showed that in all cases, the $5 \mathrm{mg}$ dose of morphine was inferior to the other three doses.

The comparison of buprenorphine $0.4 \mathrm{mg}$ with morphine $10 \mathrm{mg}$ was statistically significant at the $P=0.05$ level for the average pain relief over six hours and approached statistical significance for the average pain reduction over six hours. In both instances, buprenorphine $0.4 \mathrm{mg}$ was favored over morphine $10 \mathrm{mg}$. (Figures 1-4.)

The mean duration of relief was 5.6 and 6.3 hours for buprenorphine (0.2 and $0.4 \mathrm{mg}$ respectively) and 3.1 and 5.1 hours for morphine ( 5 and $10 \mathrm{mg}$ respectively). The median duration of relief was found to be 4.2 and 4.8 hours for buprenorphine 

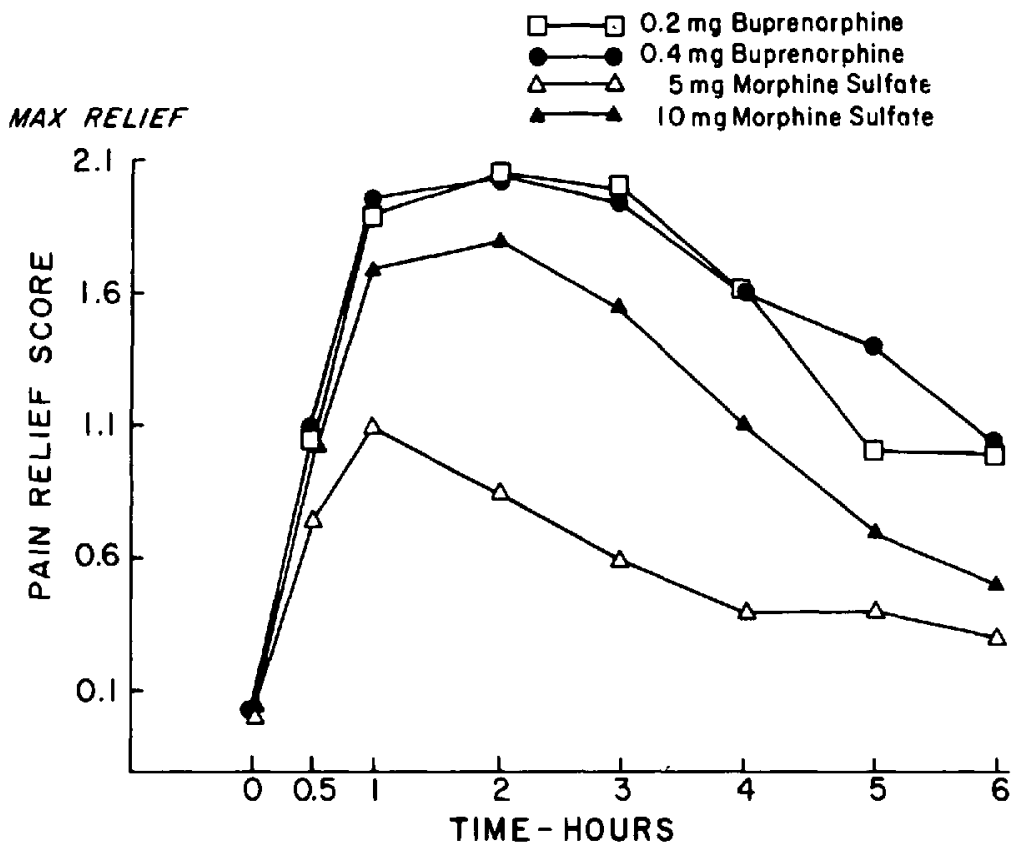

FIcune 2. Mean pain relief scores with buprenorphine and morphine during first six hours after intramuscular medication: $0=$ no relief; $1=$ slight relief; $2=$ moderate relief; $3=$ good relief; $4=$ complete relief.

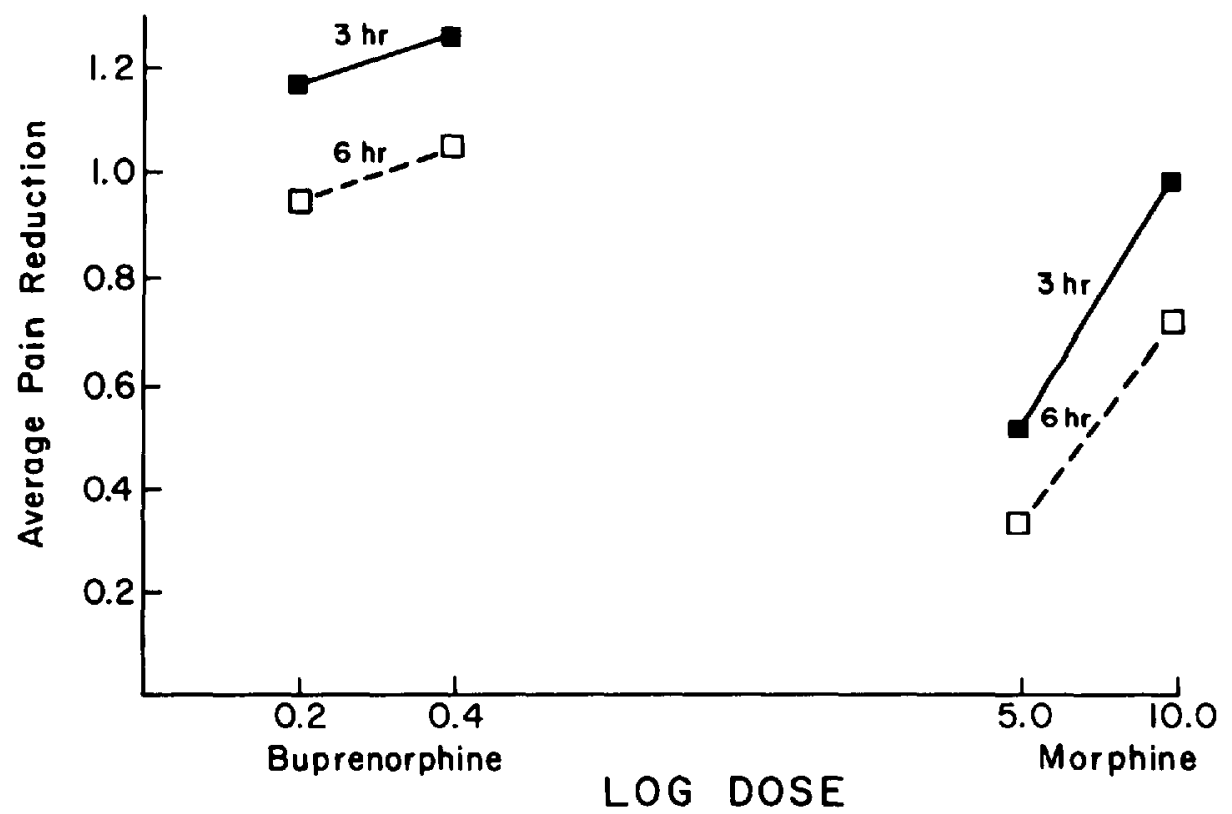

Figure 3. AVPRED 3 and AVPRED 6 vs. log dose of buprenorphine ( 0.2 and $0.4 \mathrm{mg}$ ) and morphine ( 5 and $10 \mathrm{mg}$ ). Note that $5 \mathrm{mg}$ morphine is substantially less effective than the other three medications tested. 


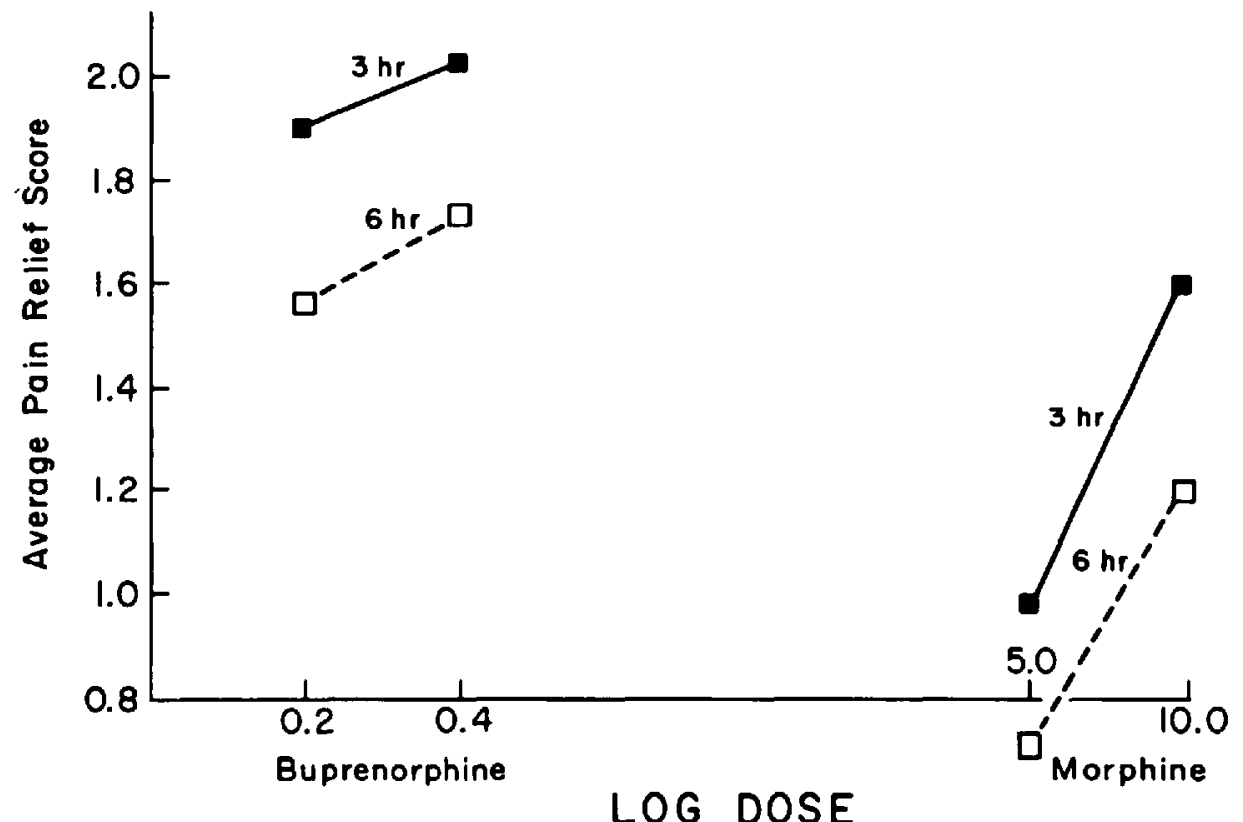

Figure 4. AVPREL 3 and AVPREL 6 vs. log dose of buprenorphine ( 0.2 and $0.4 \mathrm{mg}$ ) and morphine ( 5 and $10 \mathrm{mg}$ ).

( 0.2 and $0.4 \mathrm{mg}$ respectively) and 2.5 and 3.8 hours for morphine ( 5 and $10 \mathrm{mg}$ respectively). A median of 4.8 hours for $0.4 \mathrm{mg}$ buprenorphine implies that 50 per cent of the patients required no additional analgesic medication before 4.8 hours. (Figure 5.)

Over-all, both doses of buprenorphine were superior to morphine $5 \mathrm{mg}$ and at least as good as morphine $10 \mathrm{mg}$. Both doses of buprenorphine appeared to produce very similar responses.

Since both doses of buprenorphine appeared so similar, potency estimation was somewhat difficult. Graphical display of the adjusted means plotted against logdose suggested that between 0.11 and $0.18 \mathrm{mg}$ of buprenorphine is equivalent to morphine $10 \mathrm{mg}$. In other words, buprenorphine is at least 50 times more potent than morphine.

In the assessment of sedation and vital sign data, nothing extraordinary was seen. Buprenorphine appeared to produce more sedation than morphine but the degree of sedation was not inordinately high. The buprenorphine average sedation was only one-fourth of the way from "alert" to "mildly drowsy." No undesirable effects were seen in respiratory rate or blood pressure. Both drugs appeared to decrease the pulse rate somewhat by one hour. The incidence of side effects was essentially the same for both drugs ( 11 per cent for buprenorphine and 12 per cent for morphine). Drowsiness was the only frequent side effect. Nausea and/or vomiting occurred in seven patients who received morphine and in four patients who received buprenorphine.

The Duncan Multiplc comparisons on the raw means for AVPRED 3, AVPREL 3, AVPREL 6 and R-Time parameters confirmed that buprenorphine $0.2 \mathrm{mg}$ and 


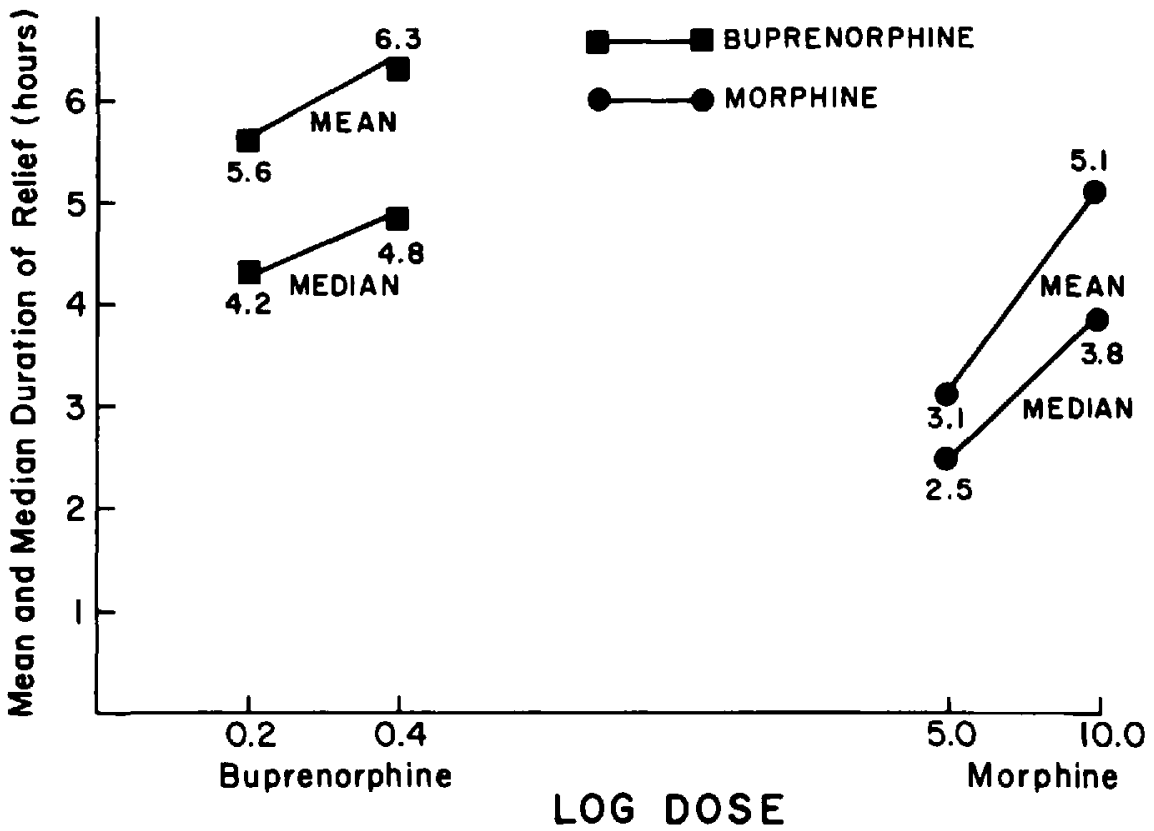

Figure 5. R-Time = Duration of relief of pain in hours vs. log dose by buprenorphine $(0.2$ and $0.4 \mathrm{mg}$ ) and morphine $(5$ and $10 \mathrm{mg}$ ). This represents the time interval between test drug injection and next analgesic administration.

$0.4 \mathrm{mg}$ and morphine $10 \mathrm{mg}$ were clearly different from morphine $5 \mathrm{mg}$ in analgesic activity.

\section{Discussion}

Assessing pain intensity has troubled the clinical investigator for many years. ${ }^{4-7}$ It is, therefore, important to test analgesics on patients in whom there is no reasonable doubt that the person has a good objective reason for complaining of pain. Such is the case almost invariably after elective abdominal surgery. ${ }^{10-12}$ Relief of pain by drugs is usually somewhat easier to assess both objectively and subjectively, but one must still depend primarily on the patient's statements at interview for valid use of current scoring systems. ${ }^{4,5}$ Long interviews and word association tests are inappropriate for evaluating pain medication in the postoperative patient. ${ }^{13,14,15}$

Since the four groups obtained in this study were statistically comparable in all respects, the analysis of the pain intensity and pain relief scores could render reliable data. Employing recognized statistical tests and from examination of the graphed score data it appears that valid conclusions may be drawn, viz: that buprenorphine is at least 50 times more potent than morphine and that its analgesic activity is substantially longer in duration than morphine.

In other respects buprenorphine and morphine are probably quite similar (drowsiness, miosis, nausea) and cannot be differentiated easily. Neither analgesic caused appreciable changes in cardiorespiratory function.

Since buprenorphine hydrochloride can be synthesized and appears to have a 
low propensity to addiction and tolerance, it may be a useful substitute for morphine and its analgesic analogues. Buprenorphine, therefore, deserves extensive further evaluation.

\section{SummaRy AND Conclusions}

In a double-blind, random assignment study of four groups of 40 patients, relief of severe pain with buprenorphine hydrochloride $0.2 \mathrm{mg}$ or $0.4 \mathrm{mg}$ was evaluated and compared with morphine sulphate 5 or $10 \mathrm{mg}$. Evaluations included pain intensity, pain relief, sedation and other effects for up to 12 hours after drug administration, following recovery of wakefulness from anaesthesia for major abdominal surgery. Analyses of five parameters showed that the four groups were statistically comparable and that buprenorphine hydrochloride is at least 50 times more potent than morphine sulphate and has a substantially longer duration of analgesic action. Further clinical evaluation is, therefore, recommended.

\section{RÉSUMÉ}

Le chlorure de buprenorphine à des doses de 0.2 et de $0.4 \mathrm{mg}$ a été comparée à la morphine à des doses de 5 et de $10 \mathrm{mg}$, ceci après éveil de l'anesthésie et suivant une chirurgie abdominale majeure.

L'intensité de la douleur, son soulagement et la sédation produite, ainsi que les autres effets observés, ceci dans les 12 heures suivant l'administration, ont été évalués.

Cette étude à double insu, portant sur une population volontaire de 160 malades, a permis de former quatre groupes au hasard, pour fins de comparaison des agents et des doses administrées.

L'analyse de nos résultats démontre que (1) nos quatre groupes étaient statis. tiquement comparables, (2) que le chlorure de buprenorphine est au moins 50 fois plus puissant que la morphine et (3) que son action est substantiellement plus longue.

On recommande la poursuite de son évaluation clinique.

\section{ACKNOWLEDGEMENTS}

The authors are grateful to Dr. Benjamin F. Africa for his clinical assistance in this study and to Drs. Harriet Kiltie and T. Terzakis of Lederle Clinical Research Laboratory for facilitating the statistical analyses of the data. The authors also appreciate the co-operation of the nursing staff in the recovery room during this investigation.

\section{REFERENCES}

1. Doskin, A.B. Buprenorphine hydrochloride: determination of analgesic potency. Canad. Anaesth. Soc. J. 24: 186-194 (1977).

2. Lewis, J.W., Mayor, P.A., \& Haddleser, D.I. Novel analgesics and molecular rearrangements in the morphine-thebaine group 30. J. Med. Chem. 16: 12 (1973).

3. ReCKitT \& Colman: Unpublished clinical reports (1976).

4. BeEcher, H.K. Measurement of subjective responses: Quantitative effects of drugs. New York, Oxford University Press ( 1959 ). 
5. Lasagna, L. The clinical measurement of pain. Ann. N.Y. Acad. Sci. 86: 28 (1960).

6. LASAGNa, L. The clinical evaluation of morphine and its substitutes as analgesics. Pharmacol, Rev. 16: 47 (1964).

7. Foldes, F.F., Swerdlow, M., \& Siker, E.S. Assessment of analgesia in narcotics and narcotic antagonists. Springfield, Illinois. C.C. Thomas, pp. 113-123 (1964).

8. BARr, A.J. \& Goodnight, J.H. A user's guide to the statistical analysis system. North Carolina State Univ., Raleigh, N.C. 27607 (1972).

9. O'Netlt, R. \& Wethenill, G.B. The present state of multiple comparison analysis. J. Roy Statistics Soc. 33: 218 (1971).

10. Simpson, B.R.J. \& Parkhouse, J. The problem of post-operative pain. Brit. J. Anaesth. 33: $336(1961)$.

11. Parkhouse, J., Lambrechts, W., \& Simpson, B.R.J. The incidence of post-operative pain. Brit. J. Anaesth. 33: 345 (1961).

12. Swerdow, M. The relief of pain after abdominal surgery. Anesth. \& Analg. 42: 588 (1963).

13. Melzack, R. The puzzle of pain. Basic Books Inc., New York, N.Y. (1974).

14. Melzack, R. \& Torgerson, W.S. On the language of pain. Anesthesiology 34: 50 (1971).

15. Clank, W.C. Pain sensitivity and the report of pain. Anesthesiology 40:272 (1974). 